\title{
Primary hepatic mixed germ cell tumor in an adult
}

\author{
Hyun-Jung Sung ${ }^{1}$, Jihun $\mathrm{Kim}^{1}$, Kyu-rae Kim ${ }^{1}$, Shinkyo Yoon ${ }^{2}$, Jae Hoon Lee ${ }^{3}$, Hyo Jeong Kang ${ }^{1,4}$ \\ Departments of ${ }^{1}$ Pathology, ${ }^{2}$ Oncology, and ${ }^{3}$ Surgery, ${ }^{4}$ Asan Liver Center, Asan Medical Center, University of Ulsan College of Medicine, Seoul, Korea
}

\begin{abstract}
Primary hepatic mixed germ cell tumor (GCT) is very rare, and less than 10 cases have been reported. We report a case of mixed GCT composed of a choriocarcinoma and yolk sac tumor, which occurred in the liver of a 40 -year-old woman. A large mass was detected by computed tomography solely in the liver. Serum $\beta$-human chorionic gonadotropin ( $\mathrm{hCG}$ ) was highly elevated, otherwise, other serum tumor markers were slightly elevated or within normal limits. For hepatic choriocarcinoma, neoadjuvant chemotherapy was administered, followed by right lobectomy. Histologic features of the resected tumor revealed characteristic choriocarcinoma features with diffuse positivity for hCG in the syncytiotrophoblasts and diffuse positivity for $\alpha$-fetoprotein and Sal-like protein 4 in the yolk sac tumor components. Primary malignant GCT in the liver is associated with a poor prognosis and requires specific treatment. Therefore, GCT should be considered during a differential diagnosis of a rapidly growing mass in the liver.
\end{abstract}

Key Words: Germ cell tumor; Choriocarcinoma; Yolk sac tumor; Liver; Adult

Received: March 31, 2021 Revised: June 15, 2021 Accepted: June 16, 2021

Corresponding Author: Hyo Jeong Kang, MD, PhD, Department of Pathology, Asan Medical Center, University of Ulsan College of Medicine, 88 Olympic-ro 43 gil, Songpa-gu, Seoul 05505, Korea

Tel: +82-2-3010-1115, Fax: +82-2-472-7898, E-mail: d100478hjk@gmail.com

Germ cell tumors (GCTs) are currently hypothesized to originate from misplaced primordial germ cells [1]. GCTs usually occur in the gonads. However, GCTs can occur in many extragonadal sites, including the hepatobiliary system, retroperitoneum, and mediastinum from misplaced primordial germ cells during their migration to the gonad [2]. GCTs in the liver are uncommon and constitute less than $1 \%$ of all hepatic neoplasms [3]. Most of the reported cases occurred in young children before 3 years of age, and about half of the cases were malignant [4]. Among them, mixed GCTs are extremely rare, and fewer than five cases of mixed GCTs have been reported in the English literature [2-5]. Previously reported mixed GCT primarily had a mature or immature teratoma component $[4,5]$. In adults, only one yolk sac tumor case with an immature teratoma has been reported [4]. Herein, we report the first case of primary hepatic mixed GCT composed of a choriocarcinoma and yolk sac tumor in a middleaged Korean woman.

\section{CASE REPORT}

A 40-year-old female patient visited an outside hospital and presented with a 1-month history of uncontrolled abdominal pain. The patient was previously healthy without any notable medical history and her obstetric history was G1P0 with one miscarriage due to spontaneous abortion. She was referred to the Asan Medical Center and computed tomography (CT) indicated that she had a very large liver mass. Her serum $\beta$-human chorionic gonadotropin (hCG) was highly elevated $(204,200 \mathrm{mIU} / \mathrm{mL}$; normal range, $<3 \mathrm{mIU} / \mathrm{mL}$ ). Other serum tumor markers of alphafetoprotein (AFP, $39.8 \mathrm{ng} / \mathrm{mL}$; normal range, <7.5 ng/mL) and prothrombin induced by the absence of vitamin $\mathrm{K}$ (PIVKA-II, $42 \mathrm{mAU} / \mathrm{mL}$; normal range, $<40 \mathrm{mAU} / \mathrm{mL}$ ) were slightly elevated, while the levels of serum carbohydrate antigens (CA19-9) and carcinoembryonic antigens (CEA) were within normal limits. Magnetic resonance imaging showed a growing mass that measured $15 \times 8.5 \mathrm{~cm}$ in the right lobe with multiple intrahepatic metastases in segment IV and the right lobe, which is not a radiological specific finding for hepatocellular carcinoma (Fig. 1A). Positron emission tomography-computed tomography (PETCT) did not show any extrahepatic lesions. In addition, gynecological ultrasonography did not detect any gestational lesions or malignancy. A target liver biopsy showed nearly all necrotic tis- 

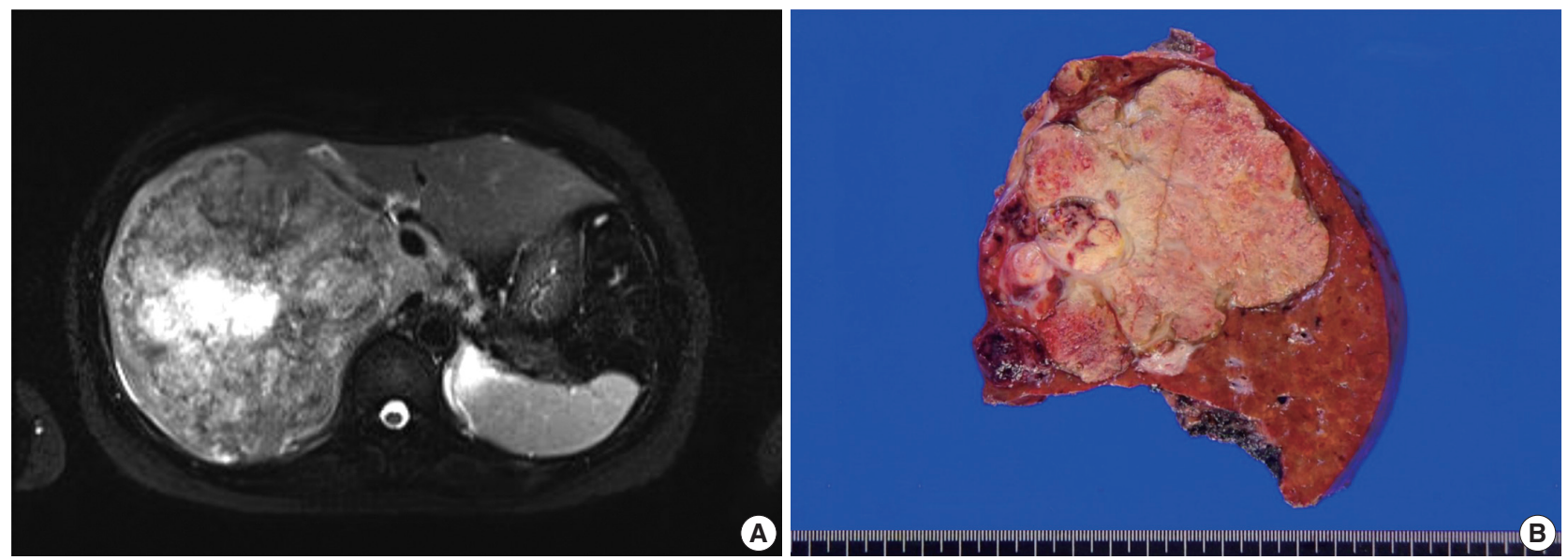

Fig. 1. Radiologic and gross findings. (A) Magnetic resonance image shows hepatomegaly with a large hypervascular mass in the right lobe. (B) The cut surface of a slice from a surgically resected specimen shows a heterogenous pinkish-yellow color, extensive necrosis, and hemorrhage.
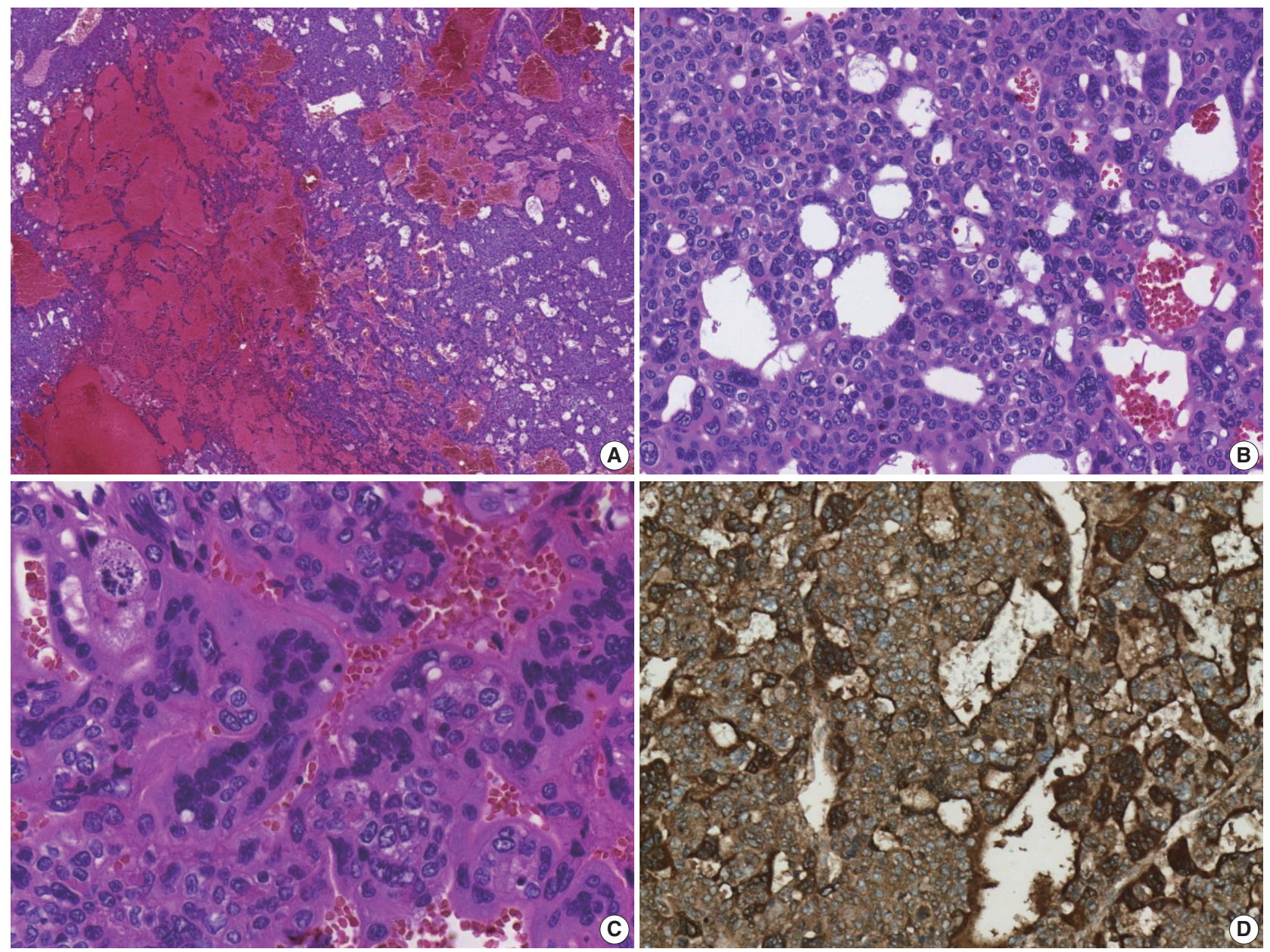

Fig. 2. Microscopic and immunohistochemical $(\mathrm{IHC})$ findings of the choriocarcinoma area. (A) Tumor cells are accompanied by extensive hemorrhage. (B) Tumor cells consist of a mixture of syncytiotrophoblastic and cytotrophoblastic cells. (C) The syncytiotrophoblastic cells are multinucleated with pleomorphic nuclei. (D) $\beta$-Human chorionic gonadotropin $॥ \mathrm{HC}$ staining is strongly and diffusely positive. 
sue with only a few atypical cells that were diagnosed as insignificant. Based on the clinical information, she was diagnosed with primary hepatic choriocarcinoma, and the patient received neoadjuvant chemotherapy (etoposide, methotrexate, actinomycin D, cyclophosphamide, and vincristine, EMA-CO) before surgical resection. After nine cycles of chemotherapy, the serum $\beta$-hCG level was markedly decreased to $47 \mathrm{mIU} / \mathrm{mL}$.

The patient underwent a right hepatectomy and recovered without immediate postoperative complications. Macroscopically, the resected specimen was entirely composed of a well-demarcated and multilobulated $15 \times 8.5 \mathrm{~cm}$ solid mass. The cut surface revealed a heterogenous pinkish-yellow color, extensive necrosis, and hemorrhage (Fig. 1B). Histologically, the tumor was composed of two GCT components including choriocarcinoma and yolk sac tumors with hepatoid component variants. The choriocarcinoma area showed extensive hemorrhage (Fig. 1A) and numerous syncytiotrophoblasts surrounded by cytotrophoblasts (Fig. 2B, C). The syncytiotrophoblasts were diffusely positive for hCG in immunohistochemical (IHC) staining (Fig. 2D). The histological features of the yolk sac tumor showed endodermal sinus-like patterns with Schiller-Duval bodies (Fig. 3A). Hepatoid variant components were multifocally identified in the yolk sac tumor area (Fig. 3B). The tumor cells in the yolk sac tumor area were diffusely positivity for AFP and Sal-like protein 4 (SALL4) based on IHC staining (Fig. 3C, D). The serum $\beta$-hCG level returned to normal $(2.3 \mathrm{mIU} / \mathrm{mL})$ after surgery. Despite adjuvant chemotherapy (EMA-CO), multiple intrahepatic and pulmonary metastases were found on a follow-up CT scan on postoperative day 58 . She then received gamma knife radiosurgery for $1.2 \mathrm{~cm}$ brain metastases in the right parietal lobe on postoperative day 219, and continued adjuvant chemotherapy.
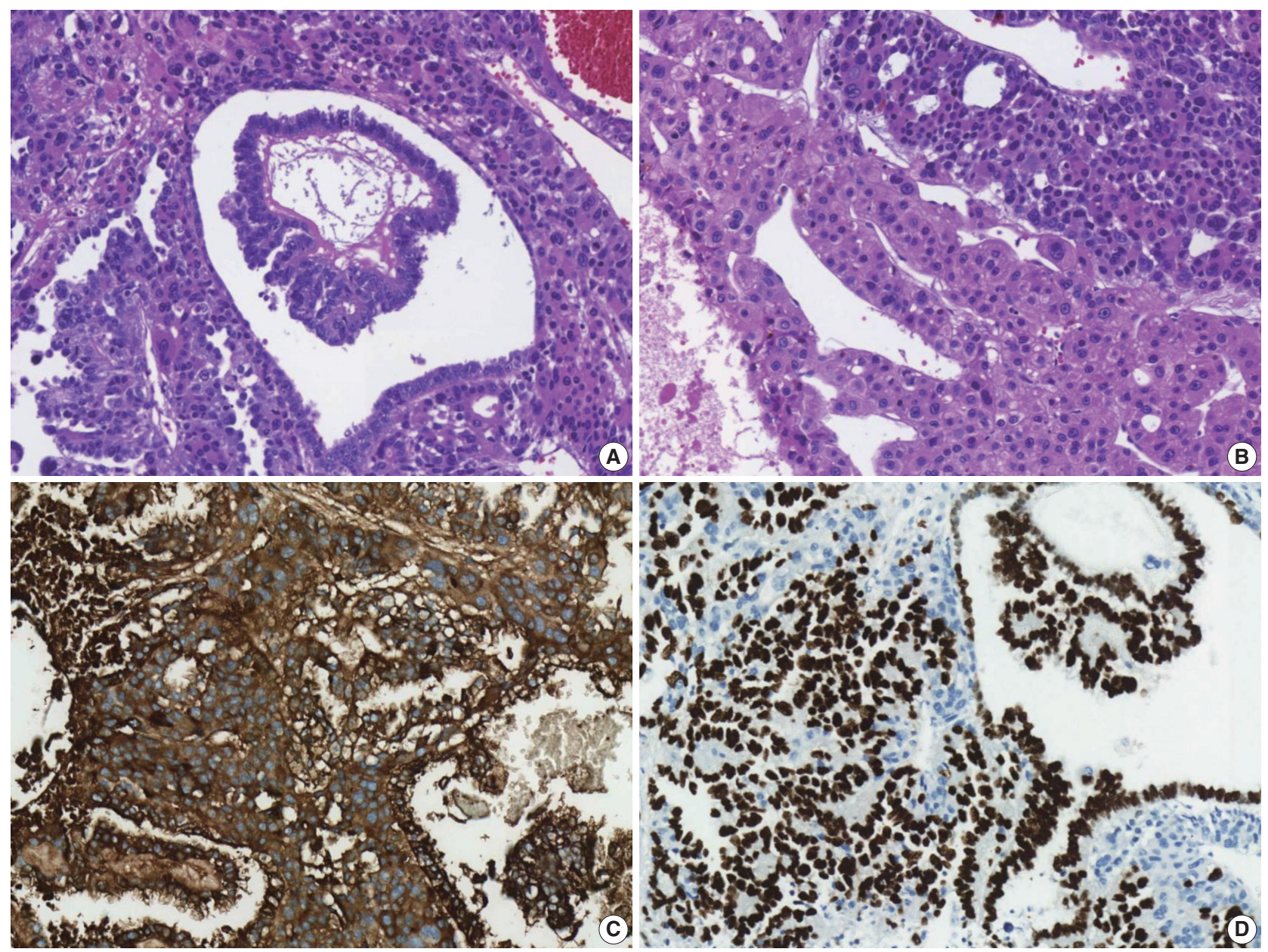

Fig. 3. Microscopic and immunohistochemical (IHC) findings of a yolk sac tumor with a hepatoid variant area. (A) A typical Schiller-Duval body is identified. (B) A hepatoid variant component of the yolk sac tumor is observed. (C) $\alpha$-Fetoprotein $\mathrm{IHC}$ staining is strongly and diffusely positive. (D) Sal-like protein $4 \mathrm{IHC}$ staining is partially positive. 
Table 1. Overview of histologically confirmed primary hepatic GCT cases in adults

\begin{tabular}{|c|c|c|c|c|c|c|c|c|}
\hline No. & Author & Age $(y r) / S e x$ & Size (cm) & Treatment & Survival & Diagnosis & Metastasis & $\mathrm{IHC}(+)$ \\
\hline 1 & Narita et al. [11] & $27 / F$ & 11 & Resection, CTx & $>12 \mathrm{mo}$ & Yolk sac tumor & No & AFP \\
\hline 2 & Villaschi and Balistreri [12] & $28 / F$ & 15 & Resection & - & Yolk sac tumor & No & SALL4 \\
\hline 3 & Wong et al. [18] & $28 / F$ & 15 & Resection & $>12 \mathrm{mo}$ & Yolk sac tumor & No & AFP \\
\hline 4 & Arai et al. [20] & $65 / M$ & - & None & 45 days & Choriocarcinoma & No & hCG \\
\hline 5 & Shi et al. [13] & 39/M & 12 & Resection, CTx & $6 \mathrm{mo}$ & Choriocarcinoma & No & $\mathrm{hCG}$ \\
\hline 6 & Shi et al. [13] & $45 / M$ & 11 & CTx & $2 \mathrm{mo}$ & Choriocarcinoma & Lung, brain & hCG \\
\hline 7 & Shi et al. [13] & $48 / \mathrm{M}$ & 13 & CTX & $3 \mathrm{mo}$ & Choriocarcinoma & Lung & $\mathrm{hCG}$ \\
\hline 8 & Shi et al. [13] & $36 / M$ & 10 & CTx & $5 \mathrm{mo}$ & Choriocarcinoma & Peritoneum, adrenal gland & $\mathrm{hCG}$ \\
\hline 9 & Shi et al. [13] & $40 / \mathrm{M}$ & 9 & Resection, CTx & $8 \mathrm{mo}$ & Choriocarcinoma & No & $\mathrm{hCG}$ \\
\hline 10 & Bakhshi et al. [21] & $40 / \mathrm{M}$ & - & Resection & 10 days & Choriocarcinoma & No & $\mathrm{hCG}$ \\
\hline 11 & Sekine et al. [15] & $49 / M$ & 10 & Resection & $2 \mathrm{mo}$ & Choriocarcinoma & No & $\mathrm{hCG}$ \\
\hline 12 & Makhmud et al. [8] & $54 / F$ & - & Resection, CTx & - & Choriocarcinoma & Lung & $\mathrm{hCG}$ \\
\hline 13 & Kohler et al. [14] & $64 / M$ & 14.5 & Resection, CTx & $5 \mathrm{mo}$ & Choriocarcinoma & Lung & $\mathrm{hCG}$ \\
\hline
\end{tabular}

GCT, germ cell tumor; IHC, immunohistochemistry; F, female; CTx, chemotherapy; AFP, $\alpha$-fetoprotein; SALL4, Sal-like protein 4; M, male; hCG, human chorionic gonadotropin.

\section{DISCUSSION}

GCTs are germinal neoplasms that arise in the gonads and extragonadal sites. GCTs account for about $3 \%$ of neoplasms in childhood and adolescence. The incidence is bimodal, and peaks at around 2 years of age, with another peak after puberty [2]. Extragonadal GCTs commonly arise from midline structures, including the mediastinum and retroperitoneum [6].

Gastrointestinal GCTs, especially primary hepatic GCTs, are very uncommon and constitute less than $1 \%$ of hepatic neoplasms. Therefore, collective descriptions of the clinicopathological features and prognosis of these tumors are rare. The etiology, clinical course, and prognosis of hepatic GCTs are not well-understood. The possible mechanisms for the development of primary hepatic GCTs are arrest and survival of germ cell precursors at ectopic sites during embryological migration as well as proliferation of pluripotent cells [7].

When diagnosing primary hepatic GCTs, the main challenge is the differential diagnosis of primary hepatic GCT from metastasis of other organs, especially from the ovaries or testis, because hepatic GCTs are more likely to have metastasized [8]. Therefore, it is important to exclude a metastasis from gonadal origin. The patient in this report showed no notable medical history and no other tumor sites were identified after extensive preoperative imaging studies. Applying either isochromosome 12p or 12p overrepresentation by fluorescence in situ hybridization (FISH) may be helpful for diagnosing germ cell tumors $[9,10]$, but it is difficult to conduct FISH testing in most hospitals. Therefore, the primary hepatic mixed GCT in this case was diagnosed based on the clinicopathologic features and the IHC staining results.

To the best of our knowledge, this is the first report of mixed
GCT composed of choriocarcinoma and yolk sac tumors that originated in the liver of an adult. To date, only 13 cases of primary hepatic GCTs in adult case reports or case series have been reported in the literature, all of which are summarized in Table 1 [4,6,8,11-19]. Primary hepatic GCTs predominantly affect males with a male to female ratio of 2:1. The average age for the occurrence in adults was 43 years (range, 27 to 65 years). Although most patients received surgical resections and some received adjuvant chemotherapy, they had poor prognoses (mean survival, $3.64 \pm 2.49$ months).

In summary, primary hepatic GCTs should be considered during the differential diagnosis of a rapidly growing solid mass in the liver because they require different treatment approaches, compared with other primary hepatic malignancies, such as hepatocellular carcinomas and cholangiocarcinomas.

\section{Ethics Statement}

The study was approved by the Institutional Review Board of Asan Medical Center (IRB 2021-0180). Formal written informed consent was not required, with a waiver from the appropriate Institutional Review Board.

\section{Availability of Data and Material}

All data generated or analyzed during the study are included in this published article (and its supplementary information files).

\section{Code Availability}

Not applicable.

\section{ORCID}

Hyun-Jung Sung https://orcid.org/0000-0002-8791-5945 Jihun Kim https://orcid.org/0000-0002-8694-4365 Kyu-rae Kim https://orcid.org/0000-0002-5781-7447 Shinkyo Yoon https://orcid.org/0000-0001-7544-0404 Jae Hoon Lee https://orcid.org/0000-0002-6170-8729 Hyo Jeong Kang https://orcid.org/0000-0002-5285-8282 


\section{Author Contributions}

Conceptualization: HJK. Data curation: HJS. Investigation: HJS. Supervision: HJK. Visualization: HJS. Writing-original draft: HJS. Writing-review \& editing: HJK, JK, KK, SY, JHL. Approval of final manuscript: all authors.

\section{Conflicts of Interest}

The authors declare that they have no potential conflicts of interest to disclose.

\section{Funding Statement}

No funding to declare.

\section{References}

1. Murat E, Dagdemir A, Bilgici MC, Sullu Y. Primary yolk sac tumor of the retroperitoneal region. Contemp Oncol (Pozn) 2013; 17: 530-2.

2. Fanelli MC, Duarte AA, de Souza FK, et al. Primary germ cell tumor of the liver. J Pediatr Surg Case Rep 2019; 51: 101324.

3. Theegarten D, Reinacher A, Graeven U, Philippou S. Mixed malignant germ cell tumour of the liver. Virchows Arch 1998; 433: 93-6.

4. Xu AM, Gong SJ, Song WH, et al. Primary mixed germ cell tumor of the liver with sarcomatous components. World J Gastroenterol 2010; 16: 652-6.

5. Verma M, Agarwal S, Mohta A. Primary mixed germ cell tumour of the liver: a case report. Indian J Pathol Microbiol 2003; 46: 658-9.

6. Vanidassane I, Sharma V, Ramteke P, Yadav MK, Batra A. Primary yolk sac tumor of the liver in an adult man. ACG Case Rep J 2019; 6: e00050.

7. Bosman FT, Carneiro F, Hruban RH, Theise ND. WHO classification of tumours of the digestive system. Lyon: IARC, 2010.

8. Makhmud M, Shin E, Cho JY, et al. Primary hepatic choriocarcinoma in a female patient. Korean J Clin Oncol 2015; 11: 33-6.

9. Kranendonk MEG, Hackeng WM, Offerhaus GJA, et al. The decisive role of molecular pathology in presumed somatic metastases of type II testicular germ cell tumors: report of 2 cases. Diagn Pathol 2020; 15: 99.

10. Wehle D, Yonescu R, Long PP, Gala N, Epstein J, Griffin CA. Fluo- rescence in situ hybridization of $12 \mathrm{p}$ in germ cell tumors using a bacterial artificial chromosome clone 12p probe on paraffin-embedded tissue: clinical test validation. Cancer Genet Cytogenet 2008; 183: 99-104.

11. Narita T, Moriyama Y, Ito Y. Endodermal sinus (yolk sac) tumour of the liver: a case report and review of the literature. J Pathol 1988; 155: 41-7.

12. Villaschi S, Balistreri P. Endodermal sinus tumour of the liver. Histopathology 1991; 18: 86-8.

13. Shi H, Cao D, Wei L, Sun L, Guo A. Primary choriocarcinoma of the liver: a clinicopathological study of five cases in males. Virchows Arch 2010; 456: 65-70.

14. Kohler A, Welsch T, Sturm AK, et al. Primary choriocarcinoma of the liver: a rare, but important differential diagnosis of liver lesions. J Surg Case Rep 2018; 2018: rjy068.

15. Sekine R, Hyodo M, Kojima M, et al. Primary hepatic choriocarcinoma in a 49-year-old man: report of a case. World J Gastroenterol 2013; 19: 9485-9.

16. Fernandez Alonso J, Saez C, Perez P, Montano A, Japon MA. Primary pure choriocarcinoma of the liver. Pathol Res Pract 1992; 188: 375-7.

17. Natori T, Teshima S, Kikuchi Y, et al. Primary yolk sac tumor of the liver: an autopsy case with ultrastructural and immunopathological studies. Acta Pathol Jpn 1983; 33: 555-64.

18. Wong NA, D'Costa H, Barry RE, Alderson D, Moorghen M. Primary yolk sac tumour of the liver in adulthood. J Clin Pathol 1998; 51: 939-40.

19. Whelan JS, Stebbings W, Owen RA, Calne R, Clark PI. Successful treatment of a primary endodermal sinus tumor of the liver. Cancer 1992; 70: 2260-2.

20. Arai M, Oka K, Nihei T, et al. Primary hepatic choriocarcinoma: a case report. Hepatogastroenterology 2001; 48: 424-6.

21. Bakhshi GD, Borisa AD, Bhandarwar AH, Tayade MB, Yadav RB, Jadhav YR. Primary hepatic choriocarcinoma: a rare cause of spontaneous haemoperitoneum in an adult. Clin Pract 2012; 2: e73. 